\title{
Toepassings en bioveiligheid van Fe@Cu kern-in-dop nanodeeltjies
}

\section{Outeurs: \\ Dlamini N Goodman \\ Basson A Kotze \\ Moganavelli Singh ${ }^{b}$ \\ Viswanadha SR Pullabhotla \\ Affiliasies: \\ aDepartement Biochemie en \\ Mikrobiologie, Universiteit \\ van Zoeloeland, Privaatsak \\ X1001, KwaDlangezwa, \\ 3886, Suid-Afrika

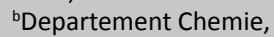 \\ Universiteit van Zoeloeland, \\ Privaatsak X1001, \\ KwaDlangezwa, 3886, \\ Suid-Afrika \\ ' Skool vir Lewensweten- \\ skappe, Universiteit van \\ KwaZulu-Natal, Privaatsak \\ X54001, Suid-Afrika* \\ Korresponderende outeur: Basson A Kotze \\ E-pos: \\ bassona@unizulu.ac.za \\ Datums: \\ Ontvang: $\quad 13 / 02 / 20$ \\ Aanvaar: $\quad 22 / 09 / 20$ \\ Gepubliseer: $11 / 11 / 20$}

Hoe om hierdie artikel aan te haal:

Dlamini N Goodman,

Basson A Kotze, Moganavelli Singh, Viswanadha SR Pullabhotla, Toepassings en bioveiligheid van Fe@Cu kern-in-dop nanodeeltjies, Suid-Afrikaanse Tydskrif vir Natuurwetenskap en Tegnologie 39(1) (2020). https://doi.org/10.36303/ SATNT.2020.39.1.784

An English copy of this paper is available online at http://www.satnt.ac.za/ index.php/satnt/article/ view/784

\section{Kopiereg:}

(C) 2020. Authors.

Licensee: Die Suid-

Afrikaanse Akademie vir

Wetenskap en Kuns.

Hierdie werk is onder

die Creative Commons

Attribution License

gelisensieer.
Die afgelope paar jaar is daar groot belangstelling by navorsers vir die verskeidenheid toepassings en interessante eienskappe van kern-in-dop (Eng. Core-shell) nanodeeltjies (CSN's) in toegepaste velde soos katalise, sensors, materiaalchemie, biologie en watersuiwering. Ons resultate dui aan dat $\mathrm{CSN}^{\prime} \mathrm{s}$ in 'n dosis van $0.2 \mathrm{mg} / \mathrm{mL}$ die doeltreffendste is vir flokkulasie in afvalwater met 'n flokkulasie-aktiwiteit (FA) van $99 \%$ oor ' $n$ wye $\mathrm{pH}$-reeks van 3-11 (suur, neutraal en alkalies). Die termostabiliteit van die vervaardigde nanomateriale (ENM's) is tussen $60-100{ }^{\circ} \mathrm{C}$ in toepassings getoets waar daar nog steeds 'n $96 \%$ flokkulasie-aktiwiteit, bevestigend van die termiese stabiliteit van die ENM's, gevind is. Die toevoeging van ' $\mathrm{n}$ katioon soos $\mathrm{Ca}^{2+}$, het die flokkulasie-aktiwiteit tot $99 \%$ verbeter. Die hoë verwyderingsdoeltreffendheid (RE) van COD, BOD, totale stikstof en fosfate is waargeneem in alle afvalwater wat ondersoek is. Die RE van kleurstowwe is groter as $93 \%$ vir alle kleurstofmonsters wat ge-evalueer is vir flokkulasie. Die ENM's het antimikrobiese aktiwiteit teen beide Gram-positiewe en Gram-negatiewe mikroorganismes getoon. Die minimum inhiberende konsentrasie (MIC) en die minimum bakteridodende konsentrasie $(\mathrm{MBC})$ is waargeneem teen 'n lae vlak van $1.563 \mathrm{mg} / \mathrm{mL}$. Sellewensvatbaarheidstudies teenoor HEK293 en MCF7 selle was effektief by lae konsentrasies, asook gedurende 'n toename in konsentrasie van ENM's.

Sleutelwoorde: Toepassing, Fe@Cu kern-in-dop, nanodeeltjies, verwyderingsdoeltreffendheid, sintese.

Applications and biosafety of the Fe@Cu core-shell nanoparticles: A broad range of applications and interesting properties of core-shell nanoparticles (CSNs) such as catalysis, sensors, material chemistry, biology, and water purification have gained the huge interest of most researchers in recent years. The aim of the study was to synthesise Fe@Cu CSNs nanoparticles using a bioflocculant and to evaluate its potential application in flocculation activity (FA), wastewater treatment, and as an antimicrobial agent. A dosage of $0.2 \mathrm{mg} / \mathrm{mL}$ Fe@Cu CSNs was found to be the most effective with 99\% FA and also has an advantage to flocculate at a wider $\mathrm{pH}$ range of 3-11 (acidic, neutral and alkaline). Thermostability of the engineered nanomaterials (ENMs) was evaluated between the temperatures range of $60-100{ }^{\circ} \mathrm{C}$, however, $96 \%$ FA was retained, indicating the thermal stability of the ENMs. The addition of cation, $\mathrm{Ca}^{2+}$, further improved the flocculation activity to the highest reading of $99 \%$. The high removal efficiency (RE) of chemical oxygen demand (COD), biochemical oxygen demand (BOD), total nitrogen and phosphate was observed in all wastewater samples examined. The removal efficiency of the dyes was found to be above $93 \%$ for all dye samples. The ENMs possess antimicrobial activity against both Gram-positive and Gramnegative microorganisms. The Minimal Inhibitory Concentration (MIC) and Bactericidal Minimal Concentration (MBC) were observed at a lower concentration of $1.563 \mathrm{mg} / \mathrm{mL}$. Cell viability against HEK293 and MCF7 was high at the lower concentration; with the increase in concentration the decrease in cell viability was observed.

Keywords: application, Fe@Cu core-shell, nanoparticles, removal efficiency, synthesis 


\section{Inleiding}

'n Belangrike aspek van lewe is water op aarde vir alle lewende organismes. Oseane bevat ongeveer $97 \%$ van alle water en slegs $1 \%$ is beskikbaar as vars water (Corcoran, 2010). Die wêreld het sedert die begin van die 21ste eeu 'n krisis van sowel kwaliteit as hoeveelheid vars water as gevolg van industrialisering, toenemende bevolking en landbou. Vloeibare en vaste afval word in elke gemeenskap geproduseer en hierdie afval bereik vars waterbronne. Afvalwater bevat voedingstowwe wat die groei van ongewenste mikroorganismes stimuleer en kan ook verbindings bevat wat giftig is, soos byvoorbeld karsinogeniese verbindings (Tchobanoglous et al., 1991).

Die belangrikste waterbesoedelingstowwe is kolloïede en is meestal kineties onstabiel, wat dit moeilik maak om te verwyder, aangesien dit nie onder swaartekrag flokkuleer nie (Santschi, 2018). Kolloïede is 'n groot uitdaging om te verwyder as gevolg van elektrokinetiese eienskappe op hul oppervlakte (Bampole en Bafubiandi, 2018). 'n Fisieschemiese tegniek, wat dikwels gebruik word om flokke te vergroot wat verwyder kan word deur sedimentasie, flotasie of filtrering, word flokkulasie genoem (Abdullah et al., 2017). In die afgelope dekade is sintetiese en chemiese flokkulante gebruik in die behandeling van afvalwater as gevolg van hoë doeltreffendheid (Okaiyeto et al., 2016). Alhoewel, sintetiese en chemiese flokkulante soos poliakrielamiedderivate en aluminiumsulfaat ' $n$ hoë doeltreffendheid het, is daar ook nadele aan verbonde vir die omgewing en die mens omdat die verbindings nie biologies afbreekbaar is nie (Guo en Yu, 2014).

Materiaalop nanoskaalgroottemet diekern(binnemateriaal) en skulpe (buitemateriaal) word tradisioneel gedefinieer as kern-in-dop nanodeeltjies (CSN's) (Wang et al., 2013). As gevolg van die merkwaardige eienskappe en toepassing in uiteenlopende gebiede, waaronder katalise, het nanomateriaal in die onlangse verlede groot aandag getrek (Galperin en Margel, 2007, Sondi en Salopek-Sondi, 2004, Li et al., 2018, Kefeni et al., 2018, Dlamini et al., 2020). Verder het navorsers die afgelope paar dekades konvensionele heterogene katalisators vanuit 'n nuwe perspektief beskou as gevolg van vinnige nanotegnologie-ontwikkeling (Gawande et al., 2015). As gevolg hiervan is gevind dat nanodeeltjies (NP's) uitstekende eienskappe besit in die rehabilitasie van afvalwater (Dlamini et al., 2019b, Tiwari et al., 2008).

Hierdie studie het ten doel om die doeltreffendheid van yster-koper ENM's in die behandeling van afvalwater en rivierwater te ondersoek vir die verwydering van kolloidale deeltjies vir watersuiwering en om die chemiese suurstofvraag (COD), biochemiese suurstofvraag (BOD) van die water te verbeter sowel as die verwydering van fosfate en totale stikstof. Verder poog hierdie studie om die bioveiligheid van ENM's te bepaal wat met behulp van 'n bioflokkulant gesintetiseer is.

\section{Materiaal en metodes Ekstraksie en suiwering van bioflokkulante}

Die bron vir die bioflokkulant was 'n bakterie wat voorheen uit die mariene omgewing in Sodwanabaai, KwaZuluNatal Provinsie, Suid-Afrika geïsoleer is. Die organisme is geïdentifiseer as Alcaligenes faecalis met behulp van nukleotiedvolgorde van die organisme se $16 \mathrm{~S}$ rRNA. Die bakteriese kultuur is bewaar by $-80{ }^{\circ} \mathrm{C}$. Die produksiemedium vir bioflokkulantproduksie is volgens die metode van Dlamini et al. (2019b) berei. Dit bestaan uit glukose (20 $\mathrm{g}), \mathrm{MgSO}_{4} \cdot 7 \mathrm{H}_{2} \mathrm{O}(0.2 \mathrm{~g}),\left(\mathrm{NH}_{4}\right)_{2} \mathrm{SO}_{4}(0.2 \mathrm{~g}), \mathrm{K}_{2} \mathrm{HPO}_{4}(5 \mathrm{~g})$, ureum $(0.5 \mathrm{~g})$, gisekstrak $(0.5 \mathrm{~g})$ en $\mathrm{KH}_{2} \mathrm{PO}_{4}(2 \mathrm{~g})$ in 'n liter gefiltreerde seewater, $\mathrm{pH}$ 8. A. faecalis $\mathrm{HCB} 2$ is ge-inokuleer in die medium en vir 3 dae by $30{ }^{\circ} \mathrm{C}$ geïnkubeer met 'n skudtempo van 160 omwentelings per minuut (opm). Die mengsel is daarna gesentrifugeer teen 5000 opm by $4{ }^{\circ} \mathrm{C}$ vir 30 minute. Daarna is die supernatant onttrrek en in $2000 \mathrm{~mL}$ etanol gevoeg vir ekstraksie en toegelaat om by $4{ }^{\circ} \mathrm{C}$ oor 12 uur neerslag te vorm. Die gefiltreerde onsuiwer bioflokkulant is vakuum gedroog en opgelos in $100 \mathrm{~mL}$ gedistilleerde water, 'n mengsel van $79 \mathrm{~mL}$ chloroform en $21 \mathrm{~mL}$ butanol is bygevoeg en 12 uur by kamertemperatuur gelaat om te presipiteer en vakuum gedroog na filtrering. Hierdie bioflokkulant is gebruik vir die sintese van ENM's.

\section{Sintese van ENM's}

Om beide yster- en koper-NP's te sintetiseer, is 'n reeks stappe gevolg soos beskryf deur Dlamini et al. (2019a). Oplossings van kopersulfaat $\left(\mathrm{CuSO}_{4}\right)$ en ystersulfaat $\left(\mathrm{FeSO}_{4}\right)$ is gebruik. 3.0 millimolaar van elke oplossing is afsonderlik voorberei en is in 'n koniese fles by $0.5 \mathrm{~g}$ suiwer bioflokkulant gevoeg. ' $n$ Kontrole is berei deur die $\mathrm{CuSO}_{4}$ en $\mathrm{FeSO}_{4}$ weg te laat. Die gesintetiseerde NP's is vir 15 minute by $4{ }^{\circ} \mathrm{C}$ teen 4000 opm gesentrifugeer (Dlamini et al., 2019b). Om ENM's te sintetiseer, word 'n soortgelyke metode met wysigings gebruik soos beskryf deur $\mathrm{Yu}$ et al. (2017). 3.0 Millimolaar oplossings van $\mathrm{CuSO}_{4}$ met volumes van $10,20,30 \mathrm{~mL}$ is opeenvolgend by ysternanodeeltjies (FeNP's) gevoeg. Die oplossing is by kamertemperatuur vir 20 minute gelaat en daarna gesentrifugeer teen 15000 opm by $4{ }^{\circ} \mathrm{C}$ vir 30 minute.

\section{Karakterisering van ENM's}

'n BRUKER D8 Advance Diffractometer met grafietmonochromatiseerde $\mathrm{CuK} \alpha 1$-straling van golflengte $\lambda=$ $1.5406 \AA$ is gebruik om die fasesamestelling en kristalliniteit van die kern-in-dop nanodeeltjies te ondersoek. Diffraksiepatroon van die nanodeeltjies is opgeneem in die $2 \theta$-reeks van 20 tot $80^{\circ}$ met skanderingintervalle van $0.03^{\circ}$. 'n Monster van $0.1 \mathrm{ml}$ is geneem en verdun met $2 \mathrm{~mL}$ gedeïoniseerde water om die UV-vis spektrum van die nanodeeltjies te ondersoek. Die spektra, as 'n funksie van reaksietyd, is met behulp van 'n Perkin-Elmer spektrofotometer in die golflengtegebied van 300 tot $700 \mathrm{~nm}$ met 'n resolusie van $1 \mathrm{~nm}$ opgeneem. Elektronmikroskopie 
(FESEM) (JSM-6700, JEOL, Japan) is gebruik vir veldemissieskandering om gesintetiseerde NP's te ondersoek. Die gesintetiseerde NP's is op dubbelsydige kleefband gemonteer en met goud bedek in 'n spatbedekker. ' $n$ Druppel waterige oplossing wat die nanodeeltjies bevat, is op koolstofbedekte koperroosters geplaas en onder 'n infrarooi lamp gedroog (JEM 2010, JEOL, Japan) (versnelspanning $200.0 \mathrm{kV}$ ). Energiedispersiewe X-straal-analise (EDXA) gekombineer met FESEM is gebruik om die samestelling van die gesintetiseerde NP's vas te stel.

\section{Evaluering van flokkulasie-aktiwiteit van ENM's}

Kaolinklei $(4 \mathrm{~g} / \mathrm{L})$ is gebruik as die suspendeermiddel vir eksperimentering. $100 \mathrm{~mL}$ kaolienoplossing is gemeng met

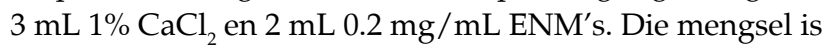
in 'n $250 \mathrm{ml}$ kegelvormige fles oorgedra en vir 1 min teen 165 opm in die skudmasjien geskud. Die mengsel is oorgedra in 'n gegradeerde maatsilinder, vir 5 minute laat staan waarna die oordekkende vloeistof met 'n spektrofotometer by $550 \mathrm{~nm}$ ontleed is. Flokkulasie-aktiwiteit (FA) is bereken volgens vgl. (1):

Flokkulasie-aktiwiteit FA $(\%)=([\mathrm{A}-\mathrm{B}]) / \mathrm{A} X 100$

Waar: A en B die optiese digtheid van onderskeidelik die monster en die kontrole by $550 \mathrm{~nm}$ verteenwoordig.

\section{Bepaling van fisies-chemiese parameters in afvalwatermonsters}

Die afvalwatermonsters is asepties versamel met behulp van steriele Schott bottels en op ys na die laboratotiun vervoer vir verdere analises. Die persele vir monsterversameling is almal in KwaZulu-Natal, Suid-Afrika, en die monsters is versamel vanaf die Mzingazirivier, Vulindlela-waterbehandelingsaanleg en afvalwater van Tendelesteenkoolmyn. Die kenmerkende eienskappe van elke watermonster voor behandeling is bepaal: Mzingazirivier (pH 7.3, absorbansie 2.8, COD $3.300 \mathrm{mg} / \mathrm{L}, \mathrm{BOD} 136 \mathrm{mg} / \mathrm{L}$, totale stikstof $0.223 \mathrm{mg} / \mathrm{L}$ en fosfate $85.7 \mathrm{mg} / \mathrm{L}$ ); Vulindlelaafvalwater as huishoudelike afvalwater $(\mathrm{pH} 6.4$, absorbansie 2,8 , totale stikstof $13,1 \mathrm{mg} / \mathrm{L}$ en fosfate $3.38 \mathrm{mg} / \mathrm{L}$ ) en Tendele-steenkoolmyn afvalwater ( $\mathrm{pH} 7.3$, absorbansie 2.9, COD $842 \mathrm{mg} / \mathrm{L}$ en BOD $123.2 \mathrm{mg} / \mathrm{L}$ ).

\section{Toepassing van ENM's in die verwydering van kleurstowwe en die behandeling van afvalwater}

Om die RE van NP's in die watermonsters te evalueer, is toetsstelle gebruik vir COD, BOD, fosfaat en totale stikstof volgens die vervaardiger se protokol in 'n UV-Vis-spektrofotometer( Pharo 300 Spectroquant ${ }^{\circledR}$ ) by $680 \mathrm{~nm}$. Vir RE van kleurstowwe is verskillende kleurstofmonsters teen $4 \mathrm{~g} / \mathrm{L}$ in gedistilleerde water opgelos. $100 \mathrm{~mL}$ van hierdie oplossings is met $2.0 \mathrm{~mL} 0.2 \mathrm{mg} / \mathrm{ml} \mathrm{ENM's} \mathrm{in} \mathrm{'n} 250 \mathrm{~mL}$ kegelfles gemeng en vir $1 \mathrm{~min}$ teen 165 opm geskud. Die mengsel is oorgedra in 'n gegradeerde maatsilinder en vir 10 minute gelaat waarna die supernatant geanaliseer is met behulp van 'n spektrofotometer op die maksimum absor- bansiemaksimum vir elke kleurstof (Dlamini et al., 2019b). Die RE is bereken deur die volgende vergelyking:

$\operatorname{RE}(\%)=(\mathrm{C} 0-\mathrm{C} 1) / \mathrm{C} 0 \times 100$

Waar: C0 die aanvanklike waarde en $\mathrm{C} 1$ die waarde na die flokkulasiebehandeling met ENM's behels.

\section{Antimikrobiese aktiwiteit van ENM's}

Bacillus subtilis CSM5 en Escherichia coli ATCC 25922 (1.0 $\mathrm{ml}$ ) is gebruik om die antimikrobiese vermoë van ENM's te evalueer. Die mikroorganismes is ge-inokuleer in steriele voedingsop en oornag geïnkubeer by $37^{\circ} \mathrm{C}$. Daarna is die absorbansie van die organismes aangepas met behulp van die spektrofotometer by $600 \mathrm{~nm}$ volgens die McFarlanstandaard (0.5). Om beide die minimum inhiberende konsentrasie (MIC) en die minimum bakteridodende konsentrasie (MBC) te bepaal, is die 96 mikroplaat putmetode aangewend waar ciprofloxacin $40 \%$ en gedistilleerde water onderskeidelik as 'n positiewe en negatiewe kontrole gebruik is. Eerstens was alle mikro-putte gevul met $50 \mu \mathrm{L}$ steriele voedingsop en gevolg deur die toevoeging van 50 $\mu \mathrm{L}$ inokulum van Bacillus subtilis en Escherichia coli. Vervolgens is $50 \mu \mathrm{L}$ ENM's met $0.2 \mathrm{mg} / \mathrm{mL}$ in die eerste rye van 96 putjes mikroplate bygevoeg om 'n reeks verdunnings te maak van die hoogste konsentrasie tot die laagste om te verseker dat in alle putte $50 \mu \mathrm{L}$ oorbly. Para-jodonitrotetrazolium (INT) is as indikator gebruik (Eloff, 1998). Meuller Hilton-agar is gebruik om die MBC te evalueer deur die putte, wat nie $n$ pienk kleur aandui nie, op 'n steriele agar inokuleer en inkubeer is vir $12 \mathrm{~h}$ by $37^{\circ} \mathrm{C}$. Die laagste konsentrasie nanodeeltjies wat die mikroorganismes dood maak word as die MBC- waarde beskou.

\section{Sitotoksisiteit in vitro van ENM's}

Die beskrywing volgens Daniels en Singh (2019) is gevolg om in-vitro sitotoksisiteit van ENM's te bepaal. HEK293 en MCF7 sellyne is gebruik om die sitotoksisiteit van die ENM's te bepaal. Om die selle met selsuspensies van $1 \times 10^{5}$ selle/mL konsentrasies te plaat, is 96-put plate gebruik. Met behulp van 'n tienvoudige verdunningsmetode is selle met verskillende konsentrasies van $25-100 \mu \mathrm{g} / \mu \mathrm{L}$ nanodeeltjies na 48 uur inkubasie gesaai. Vir die toediening van die nanodeeltjies is ' $n$ medium wat $1 \%$ fetale beesserum (FBS) bevat, gebruik en al die plate is 48 uur geïnkubeer. Die lewensvatbaarheid van die sel is vasgestel met die gebruik van die tetrazoliumsout (INT) (Sigma) as 'n aanduiding. $15 \mu \mathrm{L}$ MTT ( $5 \mathrm{mg} / \mathrm{mL}$ ) in fosfaatgebufferde sout (PBS) is by elke put gevoeg en vir 4 uur by $37^{\circ} \mathrm{C}$ geïnkubeer. Die medium met MTT en gevormde formazankristalle is opgelos in $100 \mu \mathrm{L}$ dimetielsulfoksied (DMSO) nadat die putte afgesuig is. Die mikroplaatleser is gebruik om die oplossing te lees en die optiese digtheid daarvan op $570 \mathrm{~nm}$ gemeet. Die volgende formule is gebruik om sellewensvatbaarheid te bepaal:

Sellewensvatbaarheid $(\%)=$ F1 / F0 X 100, waar F1 en F0 die onderskeie finale waardes is wat verkry word na en voor behandeling met die nanodeeltjies. 


\section{Sagteware en statistiese ontleding}

Al die eksperimente is in drievoud gedoen en die foutstawe in die figure toon die standaardafwykings van die data. Data is onderwerp aan eenrigting-variansie-analise met behulp van Graph Pad Prism TM 6.1. P-waardes $\leq 0.05$ is as beduidend beskou. Waardes met verskillende alfabet letters in dieselfde ry verskil aansienlik ( $\mathrm{p}<0.05)$.

\section{Resultate}

\section{Karakterisering van ENM's}

Karakterisering van die NP's is in ons vorige werk gedoen en dit het Fourier transform-infrarooispektroskopie (FTIR), Skandeer Elektronmikroskopie (SEM) en X-straaldiffraksie (XRD) ingesluit (Dlamini et al., 2020).

Die karakteriseringsdata vir die gesintetiseerde materiaal word in die vorm van 'n aanvullende bylaag verskaf.

\section{Die dosis-effek op die flokkulasie-aktiwiteit van ENM's}

Figuur 1 stel die resultate voor wat tydens die evaluering van verskillende konsentrasies van die ENM's effek het op die flokkulasie-aktiwiteit. 'n Flokkulasie-aktiwiteit van meer as $90 \%$ is waargeneem vir al die veskillende konsentrasies.

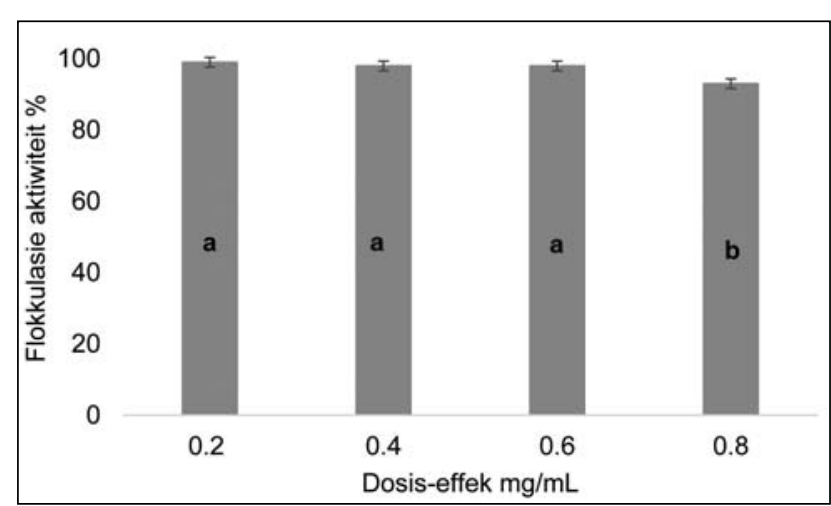

FIGUUR 1: Konsentrasie-effek op die flokkulasie-aktiwiteit van ENM's. Persentasie flokkuleeraktiwiteit met verskillende letters $(a \& b)$ is betekenisvol $(p<0,05)$ verskillend. [NB: Voeg letter $b$ in by bogen. Staafgrafiek]. [Sien Eng terme in figuur]

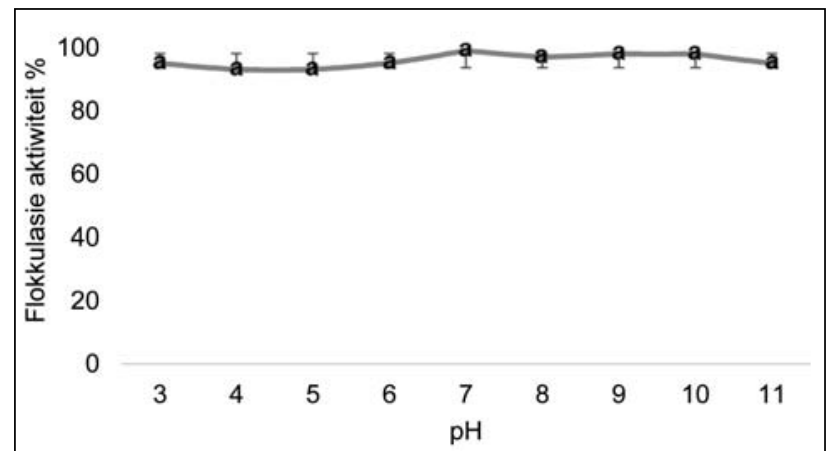

FIGUUR 2: Effek van $\mathrm{pH}$ op flokkulasie-aktiwiteit van ENM's. Persentasie flokkuleeraktiwiteite met letter (a) verskil nie beduidend nie $(p<0.05)$.

\section{Effek van toegevoegde katioon in die flokkula- sieproses}

Verskillende katione en die effek daarvan op die flokkulasieaktiwiteit word in tabel1 aangetoon. Die ENM's flokkuleer goed in die afwesigheid van 'n katioon met 'n flokkulasieaktiwiteit groter as $90 \%$.

\section{Die effek van pH op die flokkulasie-aktiwiteit van ENM's}

Die resultate in Figuur 2 toon die effek van $\mathrm{pH}$ op die flokkulasieproses. ' $\mathrm{n}$ Neutrale $\mathrm{pH} 7$ het 'n flokkulasieaktiwiteit van $99 \%$.

\section{Termostabiliteit van ENM's}

Figuur 3 toon die effek van temperatuur op die flokkulering van ENM's. Die resultate dui aan dat die nanodeeltjies hittestabiel is, aangesien die flokkulasie-aktiwiteit bo $100 \%$ was by $100^{\circ} \mathrm{C}$.

\section{Toepassing van ENM's op verwydering van kleurstof}

TABEL 1: Effek van katione op die flokkulasie-aktiwiteit van ENMs.

\begin{tabular}{c|c}
\hline Katioon & Flokkulasie-Aktiwiteit (\%) \pm SD \\
\hline Kontrole & $95 \pm 0.3^{\mathrm{a}}$ \\
$\mathrm{Fe}^{3+}$ & $97 \pm 0.0^{\mathrm{a}}$ \\
$\mathrm{Ca}^{2+}$ & $99 \pm 0.2^{\mathrm{a}}$ \\
$\mathrm{Na}^{+}$ & $97 \pm 0.2^{\mathrm{a}}$ \\
\hline
\end{tabular}

Waardes vertennwoordigverteenwoordig gemiddelde \pm afwyking van herhaalde lesings.

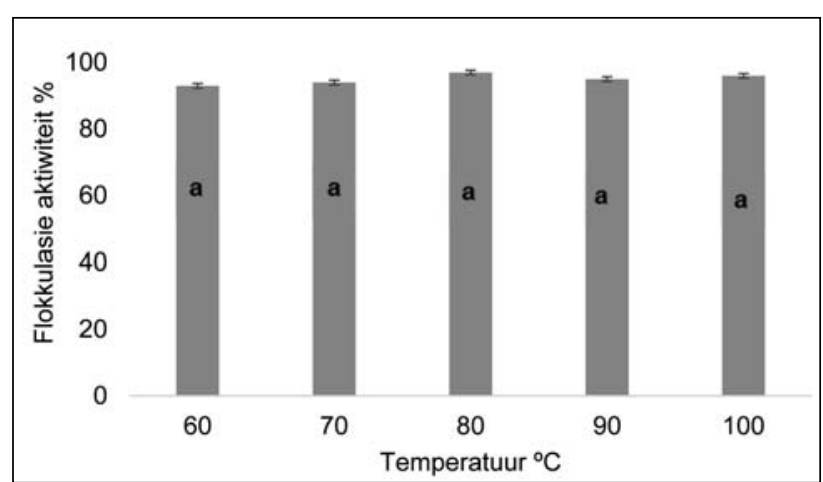

FIGUUR 3: Effek van temperatuur op die flokkulasie-aktiwiteit van ENM's. Persentasie flokkulasie-aktiwiteite met letter (a) verskil nie beduidend nie $(p<0.05)$.

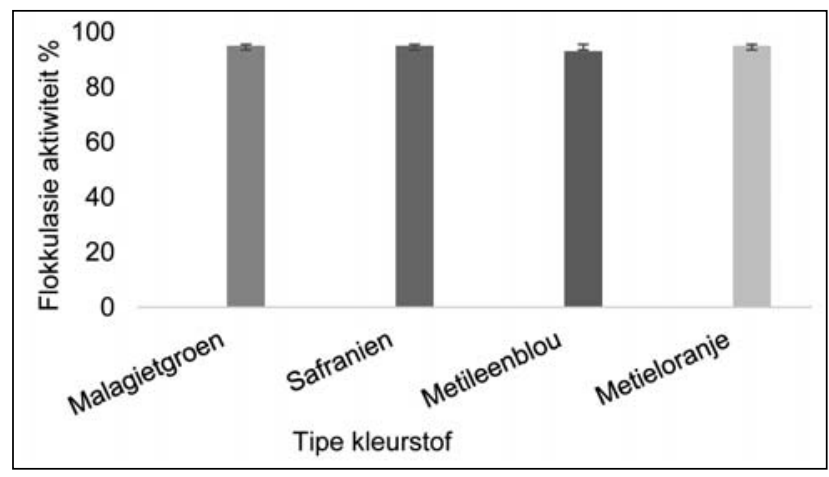

FIGUUR 4: Die resultate stel die verwydering van kleurstowwe deur ENM's voor. Die as-gesintetiseerde nanodeeltjies het $n$ verwyderingsdoeltreffendheid van meer as $90 \%$ vir alle kleurstowwe getoon. Met $95 \%$ as die hoogste vir malagietgroen, safranien en metileenoranje en die laagste verwydering met $93 \%$ vir metileenblou. 


\section{In-vitro sitotoksisiteitsevaluering van ENM's op HEK 293 en MCF7}

Die resultate van minimum inhiberende konsentrasie (MIC) en minimum bakteriosidodende konsentrasie (MBC) van die nanodeeltjies word in Tabel 2 aangetoon. Die ENM's toon goeie resultate vir MIC en MBC vir beide die Gram-positiewe en Gram-negatiewe mikroorganismes

\section{Bespreking}

'n Flokkulant met uitstekende effektiwiteit by 'n lae konsentrasie is ' $n$ noodsaaklikheid in die behandeling van afvalwater. Uit Figuur 1 het ENM's 'n paar interessante vermoëns aan die lig gebring wanneer dit teen kaolienklei getoets is, aangesien flokkulasie-aktiwiteit van $99 \%$ bereik is met slegs $0.2 \mathrm{mg} / \mathrm{mL}$ ENM's. Met die toename in konsentrasie, is ' $n$ effense afname in flokkulasie-aktiwiteit waargeneem en die laagste flokkulasie-aktiwiteit $(90 \%)$ is by die hoogste konsentrasie waargeneem $(0,8 \mathrm{mg} / \mathrm{ml})$ wat nog steeds op effektiewe werking dui. ' $n$ Verdere toename in ENM's konsentrasie sal waarskynlik lei tot beperkte vorming van die vlokke as gevolg van oortollige flokkulant wat meeding om bindingsposisies op die kolloidale deeltjies in die water (Guibai en Gregory, 1991). Uit Figuur 1 kan afgelei word dat die ENM's kommersieel lewens-

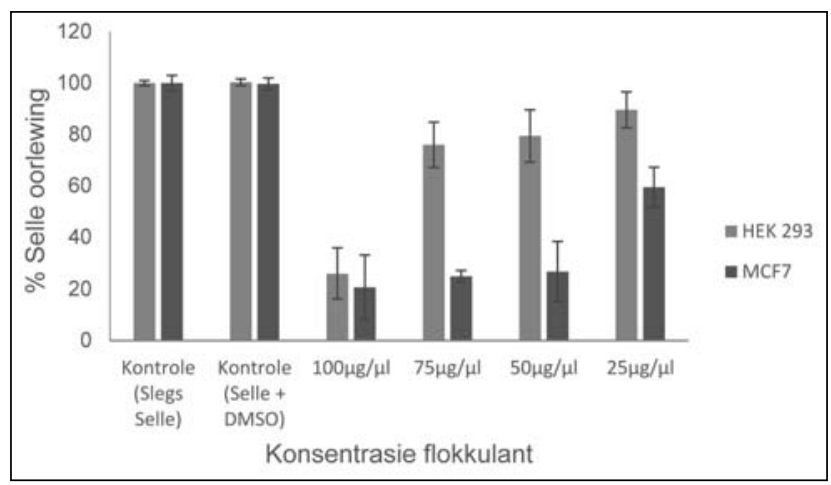

FIGUUR 5: In vitro sitotoksisiteit van ENM's op HEK 293 en MCF7 selle.

TABEL 2: Die antimikrobiese effek van ENM's.

\begin{tabular}{l|c|c|c}
\hline Antimikrobiese agent & Mikroorganisme & MIC $(\mathrm{mg} / \mathrm{mL})$ & $\mathrm{MBC}(\mathrm{mg} / \mathrm{mL})$ \\
\hline Fe@Cu Kern-in-dop & E. coli & 1.563 & 1.563 \\
& B. subtilis & 1.563 & 1.563 \\
\hline Ciprofloksasien & E. coli & 12.5 & 12.5 \\
& B. subtilis & 6.25 & 6.25 \\
\hline
\end{tabular}

vatbaar is, aangesien dit effektief is teen die laagste konsentrasie.

Katioonteenwoordigheid is ook belangrik vir die flokkulasieproses. Die katioon neutraliseer die lading van beide die kaoliensuspensie en die flokkulant, wat weer die vorming van flokke vergemaklik (Manivasagan et al., 2015). In Tabel 1 het al die geëvalueerde katione, in die verskillende oksidasie toestande, die flokkulasieproses vergemaklik, met $\mathrm{Ca}^{2+}$ die mees effektiefste (99\%). Die ENM's kon egter goed flokkuleer in die afwesigheid van katione, aangesien die kontrole 95\% flokkulasie-aktiwiteit getoon het. Soos aangetoon in Tabel 1, is die statistiese beduidendheid van die flokkulasie-aktiwiteit nie so opmerklik soos in die standaard afwykings aangedui word nie. Dit maak die ENM's 'n moontlike alternatief vir sommige chemiese flokkulante, waar bevind is dat hulle neurotoksies, kankerverwekkend en omgewingsonvriendelik is (Shevah, 2016). Soortgelyke resultate is gedokumenteer in 'n studie deur Dlamini et al. (2019b), wat aangetoon het dat koper-nanodeeltjies 'n flokkulasie-aktiwiteit van $96 \%$ gehad het in die afwesigheid van katioon.

Die ENM's is pH-stabiel en is geskik vir toediening van beide suur en alkaliese afvalwater. Uit Figuur 2 is dit duidelik dat 'n 95\% flokkulasie-aktiwiteit van ENM's by $\mathrm{pH} 3$ gevind is. Geringe verandering in $\mathrm{pH}$ (tussen 4-6) het gelei tot konstante flokkulasie-aktiwiteit van $93 \%$ en by pH 7 was die optimale flokkulasie aktiwiteit 99\%. Hierdie bevindings dui daarop dat die ENM's potensiële toepassings in suur mynafvalwater sowel as alkaliese water het. Figuur 2 toon ook die vermoë van ENM's om ekstreme suur- en alkaliese toestande te weerstaan.

Die termostabiliteit van ENM's nanodeeltjies is ondersoek deur blootstelling vir 30 minute by verskillende temperaturel in 'n waterbad (Figuur 3). Die flokkulasie- aktiwiteit was $90 \%$ by die verskillende temperature met'n maksimum van $97 \%$ by $80{ }^{\circ} \mathrm{C}$. Termostabiliteit van die ENM's kan toegeskryf word aan die temperatuurbestande aard van die bioflokkulant wat polisakkaried van oorsprong is, in ooreenstemming met die sinteses van die ENM's (Maliehe et al., 2019). Boonop is die aard van gebondenheid van yster en koper aan die komplekse matriks van hierdie nanomateriale ook bydraend tot die hittebestande aard van die ENM's. Die saamgestelde / kern-in-dopmateriaal kan ook

TABLE 3: Die behandeling van afvalwater met ENMs.

\begin{tabular}{|c|c|c|c|c|c|}
\hline Flokkulant & Tipe afvalwater & Tipe toets & $\begin{array}{l}\text { Waterkwaliteit voor behandeling } \\
\qquad(\mathrm{mg} / \mathrm{mL})\end{array}$ & $\begin{array}{l}\text { Waterkwaliteit na behandeling } \\
\qquad(\mathrm{mg} / \mathrm{mL})\end{array}$ & Effektiwiteit (\%) \\
\hline \multirow{3}{*}{ ENMs } & Steenkool afvalwater & $\begin{array}{l}\text { COD } \\
\text { BOD }\end{array}$ & $\begin{array}{c}842 \\
123.2\end{array}$ & $\begin{array}{c}71 \\
3.1413\end{array}$ & $\begin{array}{l}92 \\
97\end{array}$ \\
\hline & Mzingazi Rivierwater & $\begin{array}{c}\text { COD } \\
\text { BOD } \\
\text { Fosfate } \\
\text { Totale stikstof }\end{array}$ & $\begin{array}{c}3.300 \\
136 \\
85.7 \\
0.223\end{array}$ & $\begin{array}{c}0.793 \\
70 \\
0.109 \\
0.014\end{array}$ & $\begin{array}{l}76 \\
94 \\
99 \\
94\end{array}$ \\
\hline & Huishoudelike afvalwater & $\begin{array}{l}\text { Fosfate } \\
\text { Totale nitrogen }\end{array}$ & $\begin{array}{l}3.38 \\
13.1\end{array}$ & $\begin{array}{l}0.127 \\
2.096\end{array}$ & $\begin{array}{l}97 \\
84\end{array}$ \\
\hline
\end{tabular}


buitengewoon hoë temperature weerstaan (Yu en Dutta, 2011).

Tekstielbedrywe en chemiese fabrieke is een van die belangrikste oorsaaklike bronne vir die vervaardiging van groot hoeveelhede kleurstofuitvloeisels wat uiteindelik waterliggame bereik wanneer dit nie behandel word nie. Die meeste pigmentmateriaal wat tydens verwerking gebruik word, is nie net giftig vir die omgewing nie (Buthelezi et al. (2012)), maar ook nie afbreekbaar nie (Verma, 2008). Die vrygestelde tekstielafvalwater het nadelige gevolge vir die ekologiese omgewing as gevolg van kleurstowwe se toksisiteit, pigmentasie en biologies moeilik afbreekbare eienskappe. Verder word die ekosisteem deur hierdie kleurstowwe van tekstielafvalwater versteur, aangesien lig nie kan deurdring vir die proses van fotosintese vir plante nie (Merzouk et al., 2010). Die maksimum doeltreffendheid vir die verwydering van kleurstowwe van $95 \%$ is waargeneem in malagietgroen, safranien en metileenoranje. Die laagste doeltreffendheid (93\%) vir verwydering van kleurstowwe is vir metileenblou waargeneem.

Die MTT-toets is gebruik om die sitotoksisiteit van ENM's op MCF7- en HEK293-sellyne te ondersoek (Moodley en Singh, 2019). Figuur 5 toon die lewensvatbaarheid van normale selle (HEK 293) 89\% teen $25 \mu \mathrm{g} / \mu \mathrm{L}$ en tydens die verhoging van die konsentrasie ENM's het die lewensvatbaarheid afgeneem tot $75 \%$ teen $75 \mu \mathrm{g} / \mu \mathrm{L}$, wat aandui dat die nanodeeltjies veilig is om te gebruik. By die hoogste konsentrasie $100 \mu \mathrm{g} / \mu \mathrm{L}$ was die lewensvatbaarheid egter onder 50\%, wat daarop dui dat die ENM's by 'n hoër konsentrasie nie veilig is nie. In teenstelling hiermee, is gevind dat die ENM's toksies is vir kankerselle (MCF7), aangesien die lewensvatbaarheid onder $50 \%$ was by 'n konsentrasie van $50 \mu \mathrm{g} / \mu \mathrm{L}$.

Antimikrobiese aktiwiteit van ENM's is teen Grampositiewe en Gram-negatiewe mikroorganismes getoets. $40 \%$ Ciprofloksasien is as 'n positiewe kontrole gebruik terwyl $0.2 \mathrm{mg} / \mathrm{mL}$ ENM's gebruik is om die aktiwiteit te bepaal. Die ENM's blyk meer effektief te wees, aangesien beide die MIC en MBC bereik is met ' $n$ lae konsentrasie van $1.563 \mathrm{mg} / \mathrm{mL}$ vir beide E. coli en B. subtilus. In teenstelling hiermee het die resultate vir Ciprofloksasien aangetoon dat die MIC en MBC vir E. coli en B. subtilus onderskeidelik 12.5 en $6.25 \mathrm{mg} / \mathrm{mL}$ is.

Nywerhede word gewoonlik naby riviere opgerig omdat meeste industriele prosesse water verbruik sodat afvaluitvloeisels maklik in riviere gestort kan word. 'n Groot verskeidenheid besoedelingstowwe soos swaarmetale, koolwaterstowwe, alkalieë, gechlorineerde koolwaterstowwe en ander chemikalieë wat in die water beland kan die $\mathrm{pH}$ van die water baie verander (Lokhande et al., 2011). Daar is ' $n$ hoë konsentrasie van chemiese suurstofvraag (COD) en biochemiese suurstofbehoefte (BOD) in die afvalwater van die steenkoolmyn, soos aangetoon in Tabel
3.ENM's kon onderskeidelik tot $92 \%$ en $97 \%$ van die CODen BOD-behoeftes verwyder . In Mzingazi-rivierwater kan die hoë konsentrasie BOD toegeskryf word aan afval van gewasse en diere asook die afvoer van industriële afvalwater, aangesien daar plase en nywerhede naby die Mzingazirivier is. Die ENM's het tot 95\% van die BOD verwyder terwyl die doeltreffendheid van die COD 76\% was. Die totale stikstof- en fosfaatverwydering vir huishoudelike afvalwater was onderskeidelik $84 \%$ en $97 \%$, terwyl die totale doeltreffendheid van stikstof- en fosfaatverwydering vir Mzingazi-rivierwater $94 \%$ en $99 \%$ was.

\section{Opsommende gevolgtrekking}

Die ENM's in hierdie studie flokkuleer effektief by 'n lae konsentrasie van $0.2 \mathrm{mg} / \mathrm{mL}$, is katioononafhanklik, $\mathrm{pH}$ stabiel en hittebestand. ENM's toon antimikrobiese effek vir beide gram-positiewe en gram-negatiewe mikroorganismes en die MIC en MBC, by 'n lae konsentrasie van 1.563 $\mathrm{mg} / \mathrm{mL}$ is ook nie toksies vir normale selle met 'n lae konsentrasie van ENM's nie. 'n Opvallende eienskap van ENM's is om kleurstowwe (met 'n konsentrasie van $4 \mathrm{~g} / \mathrm{L}$ ) te verwyder met slegs $0.2 \mathrm{mg} / \mathrm{ml}^{\mathrm{ENM}}$ 's. ENM's is effektief in die verwydering van fosfate en stikstof en verbeter die BOD en COD van die water. Produksie van ENM's wat 'n bioflokkulant gebruik, hou 'n groot potensiaal in vir toepassing in die herwinning van afvalwater aangesien die tegniek nie kompleks is nie. Dit is nie skadelik vir die omgewing nie omrede daar geen skadelike chemikalieë tydens produksie gebruik is nie. Vir toekomstige vooruitsigte word aanbeveel dat meer karakterisering van die ENM's gedoen word en dat die meganisme van ENM's geëvalueer moet word.

\section{Skrywers se bydraes}

Konseptualisering, A.K.B. en V.S.R.P.; formele analises, N.G.D. en V.S.R.P.; ondersoek, N.G.D.; toesig, A.K.B. en V.S.R.P.; skryfwerk - oorspronklike konsep, N.G.D.; skryfwerk - resensie en redigering, V.S.R.P en AKB.; sitotoksisiteitseksperimente, M.S.

\section{Befondsing:}

Nasionale Navorsingstigting (NRF, Suid-Afrika) vir die finansiële steun (Toekenningnommer : 103691).

\section{Erkennings:}

Nkosinathi Dlamini wil graag die Raad vir Wetenskaplike en Nywerheidsnavorsing (WNNR, Suid-Afrika) erken vir die finansiële hulp in die vorm van die Ph.D. beurs. Die skrywers wil Tendele-steenkoolmyn bedank vir die verskaffing van afvalwatermonsters.

Rajasekhar Pullabhotla wil graag erkenning gee aan die NRF, Suid-Afrika vir die finansiële steun (Toekenningnommer: 103691).

Prof SS Basson vir die vertaling in afrikaans. 


\section{Belangebotsings:}

Die outeurs verklaar dat daar geen belangebotsing is nie.

\section{Verwysings}

Abdullah $\mathrm{M}$, et al. Colloids removal from water resources using natural coagulant: Acacia auriculiformis. AIP Conference Proceedings, 2017. AIP Publishing, 020243.

Bampole DL, Bafubiandi M. 2018. Removal Performance of Silica and Solid Colloidal Particles from Chalcopyrite Bioleaching Solution: Effect of Coagulant Particles from Chalcopyrite Bioleaching Solution: Effect of Coagulant
(Magnafloc Set\# 1597) for Predicting an Effective Solvent Extraction. (Magnafloc Set\# 1597) for Predin
Engineering Journal, 22, 123-139.

Buthelezi SP, Olaniran AO, Pillay B. 2012. Textile dye removal from wastewater effluents using bioflocculants produced by indigenous bacterial isolates. Molecules, 17, 14260-14274.

Corcoran E. 2010. Sick water: the central role of wastewater management in sustainable development: a rapid response assessment, UNEP/Earthprint.

Daniels AN, Singh M. 2019. Sterically stabilized siRNA: gold Nano complexes enhance c-MYC silencing in a breast cancer cell model. Nanomedicine.

Dlamini NG, et al. 2020. Optimization of Fe@ Cu Core-Shell Nanoparticle Synthesis, Characterization, and Application in Dye Removal and Wastewater Treatment. Catalysts, 10, 755 .

Dlamini NG, et atl. 2019a. Biosynthesis and Characterization of Copper Nanoparticles Using a Bioflocculant Extracted from Alcaligenis faecalis HCB2. Advanced Science Engineering and Medicine, 11, 1-7.

Dlamini NG, Basson AK, Pullabhotla VSR. 2019b. Optimization and Application of Bioflocculant Passivated Copper Nanoparticles in the Wastewater Treatment. International Journal of Environmental Research and Public Health, 16, 2185.

Eloff JN. 1998. A sensitive and quick microplate method to determine the minimal inhibitory concentration of plant extracts for bacteria. Planta medica, 64, 711713.

Galperin A, Margel S. 2007. Synthesis and characterization of radiopaque magnetic core-shell nanoparticles for X-ray imaging applications. Journal of Biomedical core-shell nanoparticles for X-ray imaging applications. Journal of Biomedical
Materials Research Part B: Applied Biomaterials: An Official Journal of The Materials Research Part B: Applied Biomaterials: An Official Journal of The
Society for Biomaterials, The Japanese Society for Biomaterials, and The Society for Biomaterials, The Japanese Society for Biomaterials, and The
Australian Society for Biomaterials and the Korean Society for Biomaterials, Australian Socie

Gawande MB, et al. 2015. Core-shell nanoparticles: synthesis and applications in catalysis and electro catalysis. Chemical Society Reviews, 44, 7540-7590.

Guibal L, Gregory J. 1991. Flocculation and sedimentation of high-turbidity waters. Water Research, 25, 1137-1143.

Guo J, Yu J. 2014. Sorption characteristics and mechanisms of Pb (II) from aqueous solution by using bioflocculant MBFR10543. Applied microbiology and biotechnology, 98, 6431-6441.

Kefeni KK, et al. 2018. Synthesis and application of hematite nanoparticles for acid mine drainage treatment. Journal of Environmental Chemical Engineering, 6 , 1865-1874.
Li Y, et al. 2018. Preparation of C@silica core/shell nanoparticles from ZIF-8 for efficient ciprofloxacin adsorption. Chemical Engineering Journal, 343, 645653

Lokhande RS, Singare PU, Pimple DS. 2011. Pollution in water of Kasardi Rive flowing along Taloja industrial area of Mumbai, India. World Environment, 1 6-13.

Maliehe TS, Basson AK, Dlamini NG. 2019. Removal of Pollutants in Mine Wastewater by a Non-Cytotoxic Polymeric Bioflocculant from Alcaligenes faecalis HCB2. International journal of environmental research and public health, 16, 4001 .

Manivasagan P, et al. 2015. Production of polysaccharide-based bioflocculant for the synthesis of silver nanoparticles by Streptomyces sp. International journal of biological macromolecules, 77, 159-167.

Merzouk B, Madani K, Sekki A. 2010. Using electrocoagulation-electro flotation technology to treat synthetic solution and textile wastewater, two case studies. Desalination, 250, 573-577.

Moodley T, Singh M. 2019. Polymeric Mesoporous Silica Nanoparticles for Enhanced Delivery of 5-Fluorouracil In Vitro. Pharmaceutics, 11, 288.

Okaiyeto K, et al. 2016. Implications for public health demands alternatives to inorganic and synthetic flocculants: bioflocculants as important candidates. Microbiology Open, 5, 177-211.

Santschi PH. 2018. Marine colloids, agents of the self-cleansing capacity of aquatic systems: Historical perspective and new discoveries. Marine Chemistry, 207 systems:

Shevah Y. 2016. Substitution of Chloride Chemicals with Degradable Bioflocculants for Sedimentation of Suspended Particles in Water. Chemistry Beyond Chlorine. Springer.

Sondi I, Salopek-Sondi B. 2004. Silver nanoparticles as antimicrobial agent: a case study on E. coli as a model for Gram-negative bacteria. Journal of colloid and interface science, $275,177-182$

Tchobanoglous G, Burton FL, Stensel H. 1991. Wastewater engineering Management, 7, 1-4.

Tiwari DK, Behari J, Sen P. 2008. Application of nanoparticles in waste water treatment 1.

Verma Y. 2008. Acute toxicity assessment of textile dyes and textile and dye industrial effluents using Daphnia magna bioassay. Toxicology and industria health, 24, 491-500.

Wang $\mathrm{H}$, et al. 2013. Exploiting core-shell synergy for Nano synthesis and mechanistic investigation. Accounts of chemical research, 46, 1636-1646.

Yu X, et al. 2017. A green approach of synthesizing of Cu-Ag core-shell nanoparticles and their sintering behaviour for printed electronics. Journal of Alloys and Compounds, 724, 365-372.

Yu YT, Dutta P. 2011. Examination of $\mathrm{Au} / \mathrm{SnO} 2$ core-shell architecture nanoparticle for low temperature gas sensing applications. Sensors and Actuators B: Chemical, 157, 444-449. 